\title{
Molecular Characterization of Embryonic Stem Cell-Derived Cardiac Neural Crest-Like Cells Revealed a Spatiotemporal Expression of an Mlc-3 Isoform
}

\author{
Stefanie Schmitteckert ${ }^{1,2}$, Cornelia Ziegler ${ }^{2}$, Gudrun A. Rappold ${ }^{1}$, \\ Beate Niesler ${ }^{1, *}$, Alexandra Rolletschek ${ }^{2,3, *}$ \\ ${ }^{1}$ Institute of Human Genetics, Department of Human Molecular Genetics, Heidelberg University Hospital, Heidelberg, Germany \\ ${ }^{2}$ Institute for Biological Interfaces 1, Karlsruhe Institute of Technology (KIT), Eggenstein-Leopoldshafen, Germany \\ ${ }^{3}$ Medical Faculty Mannheim, Mannheim, Germany
}

Background and Objectives: Pluripotent embryonic stem (ES) cells represent a perfect model system for the investigation of early developmental processes. Besides their differentiation into derivatives of the three primary germ layers, they can also be differentiated into derivatives of the 'fourth' germ layer, the neural crest (NC). Due to its multipotency, extensive migration and outstanding capacity to generate a remarkable number of different cell types, the NC plays a key role in early developmental processes. Cardiac neural crest (CNC) cells are a subpopulation of the NC, which are of crucial importance for precise cardiovascular and pharyngeal glands' development. CNC-associated malformations are rare, but always severe and life-threatening. Appropriate cell models could help to unravel underlying pathomechanisms and to develop new therapeutic options for relevant heart malformations.

Methods: Murine ES cells were differentiated according to a mesodermal-lineage promoting protocol. Expression profiles of ES cell-derived progeny at various differentiation stages were investigated on transcript and protein level. Results: Comparative expression profiling of murine ES cell multilineage progeny versus undifferentiated ES cells confirmed differentiation into known cell derivatives of the three primary germ layers and provided evidence that ES cells have the capacity to differentiate into NC/CNC-like cells. Applying the NC/CNC cell-specific marker, 4E9R, an unambiguous identification of ES cell-derived NC/CNC-like cells was achieved.

Conclusions: Our findings will facilitate the establishment of an ES cell-derived CNC cell model for the investigation of molecular pathways during cardiac development in health and disease.

Keywords: Embryonic stem cells, Mice, Neural crest, Cell differentiation

Received: May 17, 2019, Revised: August 11, 2019,

Accepted: August 25, 2019, Published online: December 31, 2019

Correspondence to Beate Niesler

Institute of Human Genetics, Department of Human Molecular Genetics, Heidelberg University Hospital, Im Neuenheimer Feld 366, Heidelberg 69120, Germany

Tel: +49-6221-5635274, Fax: +49-6221-565155

E-mail: beate.niesler@med.uni-heidelberg.de

*These authors contributed equally to this work.

(c) This is an open-access article distributed under the terms of the Creative Commons Attribution Non-Commercial License (http://creativecommons.org/ licenses/by-nc/4.0/), which permits unrestricted non-commercial use, distribution, and reproduction in any medium, provided the original work is properly cited.

Copyright (C) 2020 by the Korean Society for Stem Cell Research

\section{Introduction}

Pluripotent embryonic stem (ES) cells were first isolated in 1981 from mouse blastocyst-staged embryos $(1,2)$. They have a nearly unlimited capacity of self-renewal and the potential to differentiate into cell derivatives of the ectodermal, endodermal and mesodermal lineage, in vivo and in vitro (3). ES cell culture models offer countless possibilities for the elucidation of gene regulation and function during early developmental processes, without harming animals (4). In particular, for the examination of early 
embryonic cardiac development, ES cells represent a perfect model system as they recapitulate the programmed expression of cardiac genes, proteins, receptors and ion channels as reported for mouse embryos (5).

In one of our previous studies, murine ES cells have been differentiated until the intermediate stage $5+9 \mathrm{~d}$ according to a mesodermal-lineage promoting protocol (6). Affymetrix gene chip analysis, comparing undifferentiated vs differentiated ES cells at the multilineage progeny stage $5+9 \mathrm{~d}$, revealed the up-regulation of transcripts known to be expressed in neural crest (NC) and cardiac neural crest (CNC) cells (Rolletschek et al., unpublished data; (6)) (Supplementary Table S1). NC cells are a transient, extensively migratory and multipotent cell lineage that arises from the dorsal neural tube during early embryonic development. They are indispensable for proper early development as they give rise to a prodigious number of differentiated cell types $(7,8)$. Depending on their destination, they are classified into cranial, trunk, vagal and sacral NC cells. The caudal subpopulation of cranial NC cells, originating from the dorsal neural tube between the midotic placode and the third somite, is termed the CNC $(9,10)$. CNC cells give rise to ectomesenchymal, neuronal and smooth muscle cells and play a crucial role in cardiovascular and pharyngeal glands development. They migrate to the developing cardiac outflow tract (OFT) and the proximal great vessels via the third, fourth and sixth pharyngeal arches (11). Ablation of premigratory CNC cells in chicken embryos and quail/chicken chimeras lead to conotruncal anomalies, including impaired OFT septation (persistent truncus arteriosus), abnormal patterning of the aortic arch arteries and great arteries, hypoplasia or absence of pharyngeal pouch derivatives, abnormal heart looping and ventricular septal defects $(9,12-14)$. In addition to structural defects, myocardial dysfunctions including reduced ejection fraction, decreased L-type $\mathrm{Ca}^{2+}$ currents and contractility as well as abnormal excitationcontraction coupling have been observed $(9,12-15)$. The homozygous splotch mouse mutant $\left(\mathrm{Sp}^{2 \mathrm{H}} / \mathrm{Sp}^{2 \mathrm{H}}\right)$ represents the first mammalian model for CNC ablation phenotypes (16). $\mathrm{Sp}^{2 \mathrm{H}} / \mathrm{Sp}^{2 \mathrm{H}}$ mice carry a mutation in the Pax3 gene, which is important for induction, maintenance, migration and differentiation of NC cells during embryonic development. The majority of homozygous splotch embryos develop persistent truncus arteriosus and die in utero at day 14.5 post coitum due to impaired excitation-contraction coupling, causative for depressed myocardial function and death from cardiac failure (17-19). In humans, the CNC plays a crucial role in the pathogenesis of various syndromes such as DiGeorge Syndrome, CHARGE Syndrome and Alagille Syndrome (reviewed in (20)). ES cell-derived cell models would be perfectly suited to explore underlying pathomechanisms in detail upon which improved therapeutic options might be established.

Comparative expression analyses on mRNA and protein level verified the expression of up-regulated NC/CNC-associated markers, previously identified by Affymetrix gene chip analysis and furthermore underlined the potential of ES cells to be differentiated into NC/CNC-like cells. However, as examined NC/CNC-associated markers are not exclusively expressed in those lineages (21), we additionally applied a designated NC/CNC cell-specific antibody, termed 4E9R, to identify ES cell-derived NC/CNC-like cells unambiguously $(22,23)$.

\section{Materials and Methods}

\section{Cell culture and differentiation}

Murine ES cells of line R1 (24) were cultured in ES cell proliferation medium (Dulbecco's modified eagle medium (DMEM), 15\% fetal calf serum (FCS), $0.1 \mathrm{mM}$ non-essential amino acids (NEAA), $0.5 \mathrm{mg} / \mathrm{ml}$ penicillin/streptomycin/L-glutamine (all ThermoFisher Scientific, Waltham, Massachusetts, USA), $0.1 \mathrm{mM} \beta$-mercaptoethanol and 1.5x leukemia inhibitory factor (LIF, both from Sigma-Aldrich, St. Louis, Missouri, USA)) on Mitomycin C (Sigma-Aldrich)-treated and mitotically inactivated mouse embryonic fibroblasts (MEFs) on $0.1 \%$ gelatin (SigmaAldrich)-coated $60 \mathrm{~mm}$ tissue culture petri dishes (25). Prior to differentiation, ES cells were cultured on $0.1 \%$ gelatin-coated petri dishes only for three passages to decrease the number of MEFs. Subsequently, ES cells were differentiated according to a mesodermal-lineage promoting hanging drop protocol (600 cells/drop) (25). In brief, a cell suspension was prepared containing 600 cells in $20 \mu 1$ ES cell differentiation medium (Iscove's modified Dulbecco's medium (IMDM), 20\% FCS, 0.1 mM NEAA, 0.5 $\mathrm{mg} / \mathrm{ml}$ penicillin/streptomycin/L-glutamine (all ThermoFisher Scientific) and $450 \mu \mathrm{M}$ monothioglycerol (MTG, Sigma-Aldrich)). For embryoid body (EB) formation, cell suspension drops (600 cells/20 $\mu 1$ drop) were placed on the lid of a bacteriological $100 \mathrm{~mm}$ petri dish containing $10 \mathrm{ml} 1 \times$ PBS in the lower compartment (ThermoFisher Scientific). After two days in hanging drop culture, spherical cell aggregates (EBs) were carefully rinsed from the lid and transferred in $60 \mathrm{~mm}$ bacteriological petri dishes using ES cell differentiation medium. EB expansion was performed for three further days in suspension culture. On day five of differentiation, EBs were plated on $0.1 \%$ gelatin-coated tissue culture plates for further differ- 
entiation and expansion into multilineage progenitor cells (25). Cells were cultivated at $37^{\circ} \mathrm{C}$ in $5 \% \mathrm{CO}_{2}$ and $95 \%$ humidity. ES cell-derived progeny were harvested at several differentiation stages and lysed in respective buffers for further analyses as indicated below.

\section{Morphological analysis}

For morphological characterization of ES cell-derived multilineage progenitor cells, five days old (5d) EBs were plated separately in $0.1 \%$ gelatin-coated 24-well plates (one EB/well). The appearance of beating cardiomyocytes, skeletal muscle or neuronal cells per EB was assessed, every second or third day, by bright field microscopy using the inverted routine microscope CKX41 from Olympus (Olympus, Shinjuku, Tokio, Japan). The presence of the respective cell type per EB was counted $(25,26)$.

\section{RNA extraction and CDNA synthesis}

Total RNA was extracted from undifferentiated ES cells and their progeny at different stages using peqGOLD TriFast (VWR International, Radnor, Pennsylvania, USA) according to the manufacturer's instructions. Up to $1 \mu \mathrm{g}$ total RNA was reverse transcribed using oligo $(\mathrm{dT})_{18}$ primer and M-MLV reverse transcriptase (both ThermoFisher Scientific).

\section{Reverse transcription PCR analysis}

Reverse Transcription PCR (RT-PCR) analyses were carried out using the peqGOLD Taq-DNA-polymerase 'all inclusive' kit (VWR International). The amount of amplified PCR product was quantified in relation to the expression of the reference gene, Gapdh (Glyceraldehyde 3-phosphate dehydrogenase), using the quantification software tool TINA2.08e (Raytest, Isotopenmessgeräte $\mathrm{GmbH}$, Straubenhardt, Germany) as previously described $(27,28)$. Expression analyses were performed from undifferentiated ES cells and ES cell-derived progeny at several differentiation stages (formation of EBs in hanging drops: 2d; suspension culture and start of differentiation: $5 \mathrm{~d}$; days of differentiation: $5+2 \mathrm{~d},+4 \mathrm{~d},+7 \mathrm{~d},+9 \mathrm{~d},+11 \mathrm{~d},+14 \mathrm{~d},+18 \mathrm{~d}$, $+25 \mathrm{~d},+30 \mathrm{~d},+35 \mathrm{~d}$ ) using ten independent biological replicates. Oligonucleotide sequences and experimental details are given in Supplementary Table S2.

\section{Tissue preparation}

Female and male wildtype NMRI mice were kept according to the German animal protection ordinance (Tierschutz-Versuchstierverordnung - TierSchVersV).

Tissues were prepared at several stages post fertilization. Whole-mount embryos were prepared at embryonic stage (E) 9.5 and heart tissue was isolated at E10.5 E17.5, postnatal day (P) 8, P15 and from the adult. Primary mouse CNC cells were isolated at E10.5 and used for Western blot and immunoprecipitation (IP) analyses. Therefore, the tissue between the midotic placode and the third somite, harboring primary CNC cells, was resected from mouse embryos (E10.5) using fine preparation cutlery. Tissue specimens in general, were then either lysed in a commercially available cell disruption buffer (PARIS Protein \& RNA Isolation Kit, ThermoFisher Scientific) or in NP-40 buffer (50 mM Tris $\mathrm{pH} 8.0,5 \mathrm{mM}$ EDTA, $150 \mathrm{mM} \mathrm{NaCl}, 1 \% \mathrm{NP}-40$ ) including protease inhibitor cocktail (all from Sigma-Aldrich) for downstream protein analyses.

\section{Isolation of beating cardiac clusters}

Beating ES cell-derived cardiac cell clusters at differentiation stages $5+4 \mathrm{~d}$ and $5+7 \mathrm{~d}$ were isolated according to (29). In brief, beating cell clusters were mechanically separated and enzymatically dissociated with collagenase NB8 solution $(0.5 \mathrm{mg} / \mathrm{ml}$ collagenase NB8 (Serva Electrophoresis $\mathrm{GmbH}$, Heidelberg, Germany), $3.51 \mathrm{~g} \mathrm{NaCl}, 200$ mg KCl, $1.8 \mathrm{~g}$ Glucose (all from Merck Chemicals GmbH; Darmstadt, Germany), $615 \mathrm{mg} \mathrm{MgSO} 4,275 \mathrm{mg}$ Na-Pyruvat, $1.25 \mathrm{~g}$ Taurine, $1.19 \mathrm{~g}$ Hepes (all from Sigma-Aldrich) ad $500 \mathrm{ml}$ bidest. $\left.\mathrm{H}_{2} \mathrm{O}, \mathrm{pH} 6.9\right)$ for $20 \mathrm{~min}$. at $37^{\circ} \mathrm{C}$ in a 15 $\mathrm{ml}$ centrifuge tube. After centrifugation, the cell pellet was resuspended in $\mathrm{KB}$ medium $(634 \mathrm{mg} \mathrm{KCl}, 369 \mathrm{mg}$ Glucose, $522 \mathrm{mg} \mathrm{K}_{2} \mathrm{HPO}_{4}$ (all from Merck Chemicals $\mathrm{GmbH}$ ), $123 \mathrm{mg} \mathrm{MgSO}$, $38 \mathrm{mg}$ EDTA, $55 \mathrm{mg}$ Na-Pyruvat, $75 \mathrm{mg}$ Kreatin, $250 \mathrm{mg}$ Taurin (all from Sigma-Aldrich), ad 100 ml bidest. $\mathrm{H}_{2} \mathrm{O}, \mathrm{pH}$ 7.2) supplemented with $2 \mathrm{mM}$ ATP (Carl Roth GmbH \& Ko KG, Karlsruhe, Germany). Afterwards, resuspended cells were incubated for $1 \mathrm{~h}$ at $37^{\circ} \mathrm{C}$. Thereafter, cells in $\mathrm{KB}$ medium were mixed with ES cell differentiation medium $(1: 1)$ and transferred onto $0.1 \%$ gelatin-coated cover slips in a 24 -well plate. After $6 \sim 8$ hours at $37^{\circ} \mathrm{C}$, a complete medium change with ES cell differentiation medium was performed and cells were further cultivated. 24 hours after isolation, cells were fixed $(5+4+1 \mathrm{~d}, 5+7+1 \mathrm{~d})$ and used for immunofluorescence analyses.

\section{Immunofluorescence analyses}

For immunofluorescence (IF) analyses, differentiated ES cell specimens and isolated beating cardiac clusters (29) were fixed in $4 \%$ paraformaldehyde (PFA, SigmaAldrich)/1× PBS (ThermoFisher Scientific) for $20 \mathrm{~min}$ at room temperature (RT). Subsequently, specimens were permeabilized using $0.1 \%$ TritonX100 (Sigma-Aldrich)/1× 
PBS (except for ET-AR), blocked for $1 \mathrm{~h}$ at RT in $1 \%$ BSA (Serva Electrophoresis $\mathrm{GmbH}) / 1 \times \mathrm{PBS}$ and incubated with the respective primary antibodies for $1 \mathrm{~h}$ at RT. Primary antibodies are given in Supplementary Table S3. After washing with $1 \times$ PBS, cells were incubated at RT for $1 \mathrm{~h}$ with the following secondary antibodies: anti-rabbit, anti-goat and anti-mouse Cy3 (1:700; Dianova, Hamburg, Germany) or anti-mouse- and anti-rabbit Alexa Fluor 488 (1 : 100; Molecular Probes, Eugene, Oregon, USA). Nuclei were counterstained with DAPI (4',6-diamidino-2-phenylindole, Sigma-Aldrich) and cover slipped in Vectashield mounting medium (Biozol, Eching, Germany) for long-term storage.

For IF analyses using the 4E9R antibody (gift from Prof. Kazuo Ito, Osaka University, Japan) (22), following modifications were applied: differentiated ES cell specimens were fixed with $0.1 \%$ formaldehyde $/ \mathrm{MeOH}$ (both Sigma-Aldrich) and then rehydrated on ice. After blocking with $1 \% \mathrm{BSA} / 1 \times \mathrm{PBS}$, cells were incubated with primary antibodies overnight at $4^{\circ} \mathrm{C}$.

For visualization the Axiovert 200M fluorescence microscope from Zeiss (Carl Zeiss AG, Oberkochen, Germany) was used.

\section{Western blot analysis}

Primary CNC cells (E10.5), heart tissues (E10.5 E17.5, P8, P15, adult) as well as ES cell-derived specimens (5d-5 $+25 \mathrm{~d}$ ) were homogenized and lysed in cell disruption buffer (PARIS Protein \& RNA Isolation Kit, ThermoFisher Scientific). Protein samples $(60 \mu \mathrm{g})$ were separated by SDS-PAGE and blotted onto a PVDF membrane. Membranes were labeled either with Gapdh or 4E9R and myosin light polypeptide 6 (gene: Myl6) antibodies (Supplementary Table S3). In the following, we will refer to myosin light polypeptide 6 as Mlc-3, using an official alternative protein name (www.uniprot.org). Labeled proteins were visualized using the ECL Plus chemiluminescent substrate (Sigma-Aldrich).

\section{Immunoprecipitation}

An immunoprecipitation (IP) was performed with Lagarose (Sigma-Aldrich) according to the manufacturer's instructions. Briefly, $100 \mu \mathrm{g}$ protein lysate from E9.5 whole-mount embryos, isolated E10.5 CNC cells, embryonic heart tissue (E10.5, E11.5, and E13.5), adult heart tissue or ES cell specimens from $5+7 \mathrm{~d}$ and $5+18 \mathrm{~d}$ were lysed in NP-40 buffer. Protein lysates were incubated overnight with $4 \mathrm{E} 9 \mathrm{R}$ antibody at $4^{\circ} \mathrm{C}$. L-agarose was added and samples were incubated for further $60 \mathrm{~min}$ at $4^{\circ} \mathrm{C}$. Samples were washed and resuspended in $2 \times$ Laemmli buffer (1 M Tris pH 6.8, 10\% $\beta$-mercaptoethanol, bromphenol blue (all from Sigma Aldrich), 20\% SDS (Carl Roth, Karlsruhe, Germany), separated by SDS-PAGE and stained with Coomassie Blue (Sigma-Aldrich). Selected bands were cut out for nano-scale liquid chromatography electrospray ionization tandem mass spectrometry (nLCESI-MSMS) analysis (Proteome Factory, Berlin).

\section{nLC-ESI-MSMS analysis}

Protein identification was performed by the Proteome Factory AG (Berlin, Germany). Protein spots were in-gel digested using sequencing-grade porcine trypsin (Promega Corporation, Madison, Wisconsin, USA) and analyzed by nLC-ESI-MSMS. The LC-MS/MS system consisted of an Agilent 1100 nanoHPLC system (Agilent Technologies Deutschland GmbH, Waldbronn, Germany), PicoTip electrospray emitter (New Objective, Woburn, Massachusetts, USA) and a QStar XL mass spectrometer (Applied Biosystems, Foster City, California, USA). Peptides were trapped and desalted on the enrichment column (Zorbax 300SB-C18, $0.3 \times 5 \mathrm{~mm}$, Agilent Technologies Deutschland $\mathrm{GmbH}$ ) for five $\min$ (solvent: $2.5 \%$ acetonitrile/0.5\% formic acid), then separated on a Zorbax 300SB-C18, $75 \mu \mathrm{m}$ $\times 150 \mathrm{~mm}$ column (Agilent Technologies Deutschland $\mathrm{GmbH}$ ) using a linear gradient from $10 \%$ A to $32 \% \mathrm{~B}$ (solvent A: $0.1 \%$ formic acid in water, solvent B: $0.1 \%$ formic acid in acetonitrile, both Sigma-Aldrich). The three most abundant ions were data-dependently subjected to MS/MS according to the expected charge state distribution of peptide ions. Proteins were identified by searching the NCBInr protein database using an MS/MS ion search of the Mascot search engine (Matrix Science Ltd., London, UK). The final report contained a list of proteins with a significant Mascot ion score, which is based on the calculated probability $(\mathrm{P})$ that the monitored match between the experimental data and the database sequence is a random event. Hence, the ion score represents the negative $\log$ arithm of the probability $(-10 \log [\mathrm{P}])$ that a result could be false-positive. For reliable protein identification, the Mascot ion score should be around 100 (www. matrixscience.com).

\section{Results}

\section{Murine ES cells can be differentiated into multilineage progeny}

In order to elucidate the differentiation potential of ES cells under mesodermal lineage-promoting conditions, morphological assessment was performed by calculating the percentage of differentiating EBs showing the best dis- 
tinguishable cell types such as cardiomyocytes, skeletal muscle or neuronal cells (Supplementary Fig. S1). First beating cardiomyocytes appeared at the very early differentiation stage $5+4 \mathrm{~d}$. The beating was consistently detectable at all investigated stages, with peak occurrence between $5+9 \mathrm{~d}$ and $5+11 \mathrm{~d}$. However, due to the increasing cell number over time and the associated space limitations, the characteristic beating of cardiac clusters became difficult to detect. Thus, the apparent reduction of cardiomyocytes in later stages may not reflect the real number of this cell type (Supplementary Fig. S1, in red). Skeletal muscle cells were first observed at stage $5+9 \mathrm{~d}$ and increased constantly until last assessed differentiation stage, 5+18d (Supplementary Fig. S1, in yellow). First neuronal cells were also visible at the early differentiation stage $5+4 \mathrm{~d}$, but most were detected between $5+11 \mathrm{~d}$ and $5+14$ d (Supplementary Fig. S1, in blue). Endodermal cells are morphologically difficult to specify, so we limited our analyses to ectodermal and mesodermal cell derivatives.

In summary, the morphological determination of EBs revealed mesodermal lineage-derived ES cell progeny as well as ectodermal derivatives such as neuronal cells.

\section{Multilineage ES cell progeny express selected CNC-associated markers}

To investigate the occurrence of ES cell-derived CNClike cells, expression analyses using selected CNC-associated markers $(6,30)$ were performed (Supplementary Table S4). Selected genes have known roles in the specification (Pax3; Fig. 1A), epithelial-to-mesenchymal transition (Snail, Snai2; Fig. 1B), migration (Gjal; Fig. 1C), arterial tree remodeling (Pitx2, Ednra, Mef2c, Handl, Hand2; Fig. 1D) and myocardial development (Lbxl; Fig. 1E) (30). Comparative expression analyses revealed an up-regulation of all investigated marker genes in differentiated ES cell specimens compared to undifferentiated ES cell controls (Fig. 1A $\sim$ E). Snail, Snai2 (both Fig. 1B), Gjal (Fig. 1C), Pitx2 and Ednra (both Fig. 1D) were almost constantly expressed in all investigated differentiation stages. Expression levels of Pax3 (Fig. 1A), Mef2c, Hand1, Hand2 (all Fig. 1D) and Lbxl (Fig. 1E) increased over time until the intermediate differentiation stages $5+$ $7 \mathrm{~d}$ to $5+11 \mathrm{~d}$. In later stages the expression of those genes decreased, except for Hand2 (Fig. 1D), which showed a slight up-regulation at stage $5+35 \mathrm{~d}$.

\section{Immunoreactivity of CNC-associated markers could be verified on protein level}

Most of the selected CNC-associated markers (Supple- mentary Table S4) are not exclusively expressed in NC and $\mathrm{CNC}$ tissue, but also in other tissues and cell types, in particular in cardiac cells (21). To investigate, whether selected CNC-associated markers are also expressed in non-CNC-like cells such as cardiac, endothelial or neuronal derivatives, IF analyses were performed (Fig. 2).

For a better visualization of cardiac cell derivatives, isolated beating cardiac clusters (29) were stained. IF analyses showed strong co-expressions of the sarcomere-specific protein $\alpha$-Actinin 2 with Snai2 at the early differentiation stage 5+4+1d (Fig. 2C) and other CNC-associated markers as Snail (Fig. 2B), Cx43 (Fig. 2D), Pitx2 (Fig. 2E), Mef2c (Fig. 2G), Handl (Fig. 2H), Hand2 (Fig. 2I) and Lbx1 (Fig. 2J) at differentiation stage $5+7+1 \mathrm{~d}$. At the same stage, a co-expression of the sarcomere-specific protein Troponin T with Pax3 was observed (Fig. 2A).

IF analysis of non-isolated cardiac cells at stage $5+9 \mathrm{~d}$ revealed a partial co-expression of $\alpha$-Actinin2 with the endothelin A receptor (ET-AR) (Fig. 2F). To elucidate the expression pattern of CNC-associated markers also in non-cardiac cells, Snail (Fig. 2K), Lbxl (Fig. 2L) and Pax3 (Fig. 2M) were co-stained either with endothelial (CD144/VE-Cadherin, Fig. 2K), neuronal (Tubb3, Fig. $2 \mathrm{~L}$ ) or skeletal/cardiac muscle ( $\alpha$-Actinin2, Fig. $2 \mathrm{M}$ ) cell-specific markers. A strong co-immunoreactivity was detected for CD144 and Snail in endothelial-like cells at the early differentiation stage $5+4 \mathrm{~d}(\mathrm{Fig} .2 \mathrm{~K})$, as well as for the pan-neuronal marker Tubb3 and Lbx1 (Fig. 2L) at the more advanced differentiation stage $5+15 \mathrm{~d}$. At the same differentiation stage, a strong co-immunoreactivity in skeletal muscle cells was observed for the skeletal/cardiac muscle cell specific marker $\alpha$-Actinin2 and Pax3 (Fig. 2M).

\section{E9R immunoreactivity decreases in heart and ES cell specimens with advancing differentiation}

In order to elucidate the expression pattern of the $\mathrm{NC} /$ CNC-specific marker 4E9R in ES cell-derived progeny, ES cell specimens, as well as primary $\mathrm{CNC}$ cells at E10.5 were analyzed by Western blot (Fig. 3). The detected immunogen of $4 \mathrm{E} 9 \mathrm{R}$ had a molecular size of $\sim 15 \mathrm{kDa}$. In contrast to primary CNC cells (E10.5), undifferentiated ES cells displayed only a faint band. However, ES cell specimens at stages $5 \mathrm{~d}-5+7 \mathrm{~d}$ showed a very strong immunoreactivity for $4 \mathrm{E} 9 \mathrm{R}$. During progressive differentiation at the intermediate and more advanced stages (from $5+9 \mathrm{~d}$ to $5+21 \mathrm{~d}$ ), $4 \mathrm{E} 9 \mathrm{R}$ immunoreactivity decreased. The lowest 4E9R expression was detected at stage $5+25 \mathrm{~d}$ (Fig. 3). 


\section{A) specification}

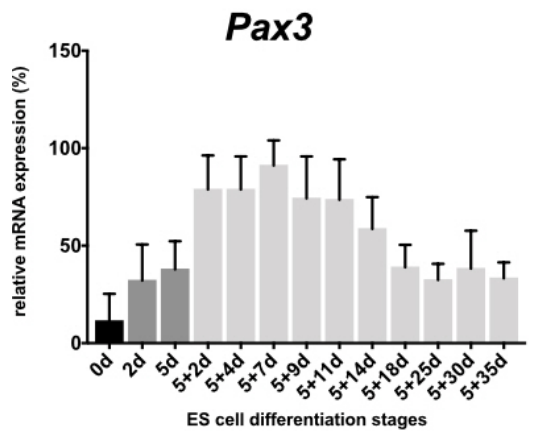

\section{C) migration}
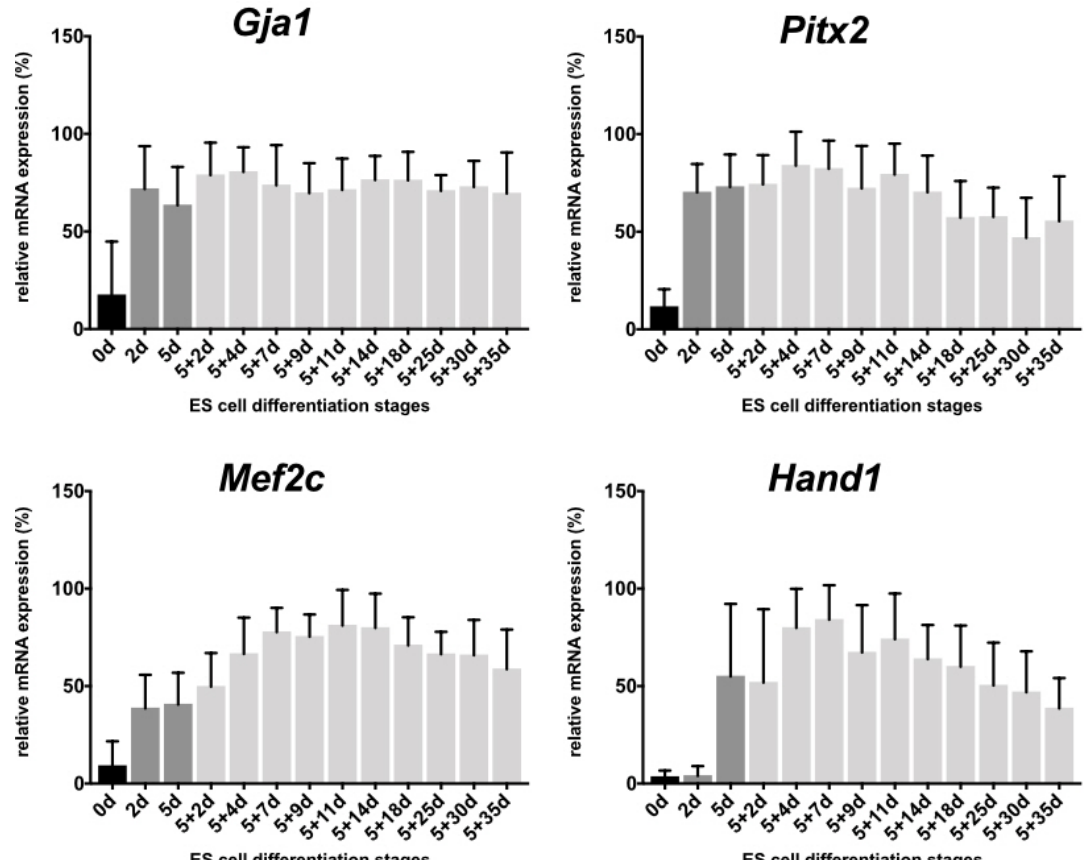
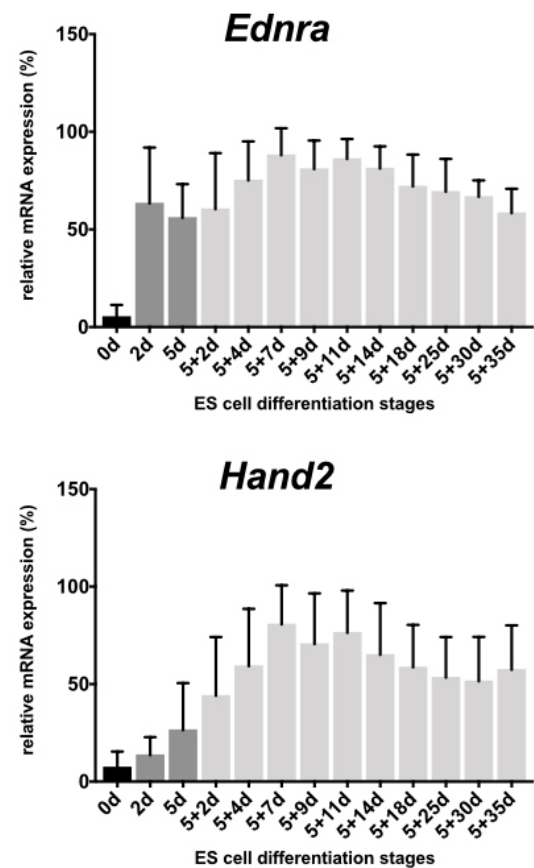

\section{E) myocardial development}

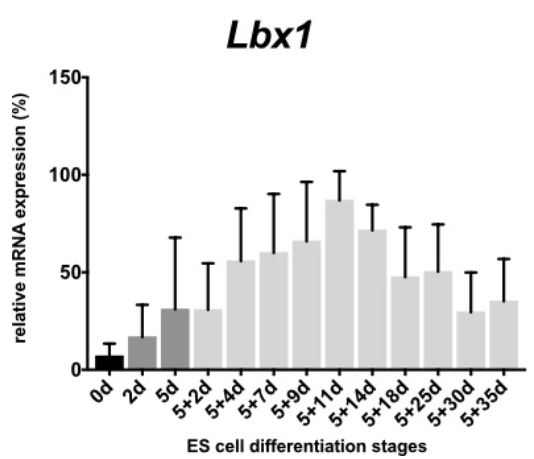

Fig. 1. Comparative expression analyses of undifferentiated ES cells and ES cell-derived progeny using selected CNC-associated markers. $(\mathrm{A} \sim \mathrm{E})$ Investigated genes were arranged according to their putative role in the CNC (adapted from (30)). Undifferentiated ES cells (0 days; d) are shown in black and embryoid body formation stages are indicated in dark grey (2d, 5d). Differentiation stages $5+2 d-5+35 d$ are shown in light grey. Column bar graphs are presenting the mean values of ten independent experiments with corresponding standard deviations. 
A, B, D, E, G-J: 5+7+1d; C: 5+4+1d; F: 5+9d
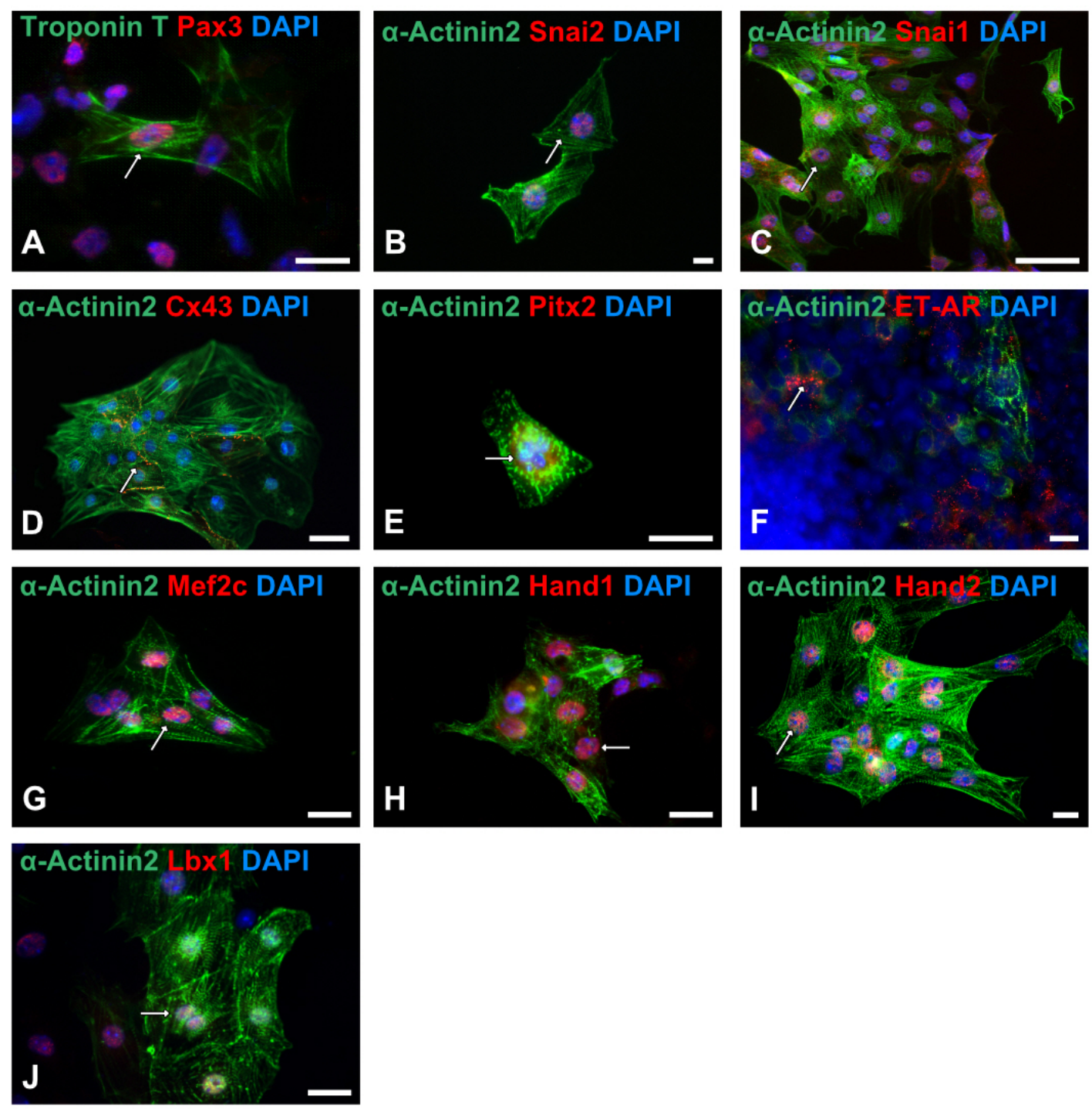

$\mathrm{K}: 5+4 d ; \mathrm{L}, \mathrm{M}: 5+15 d$
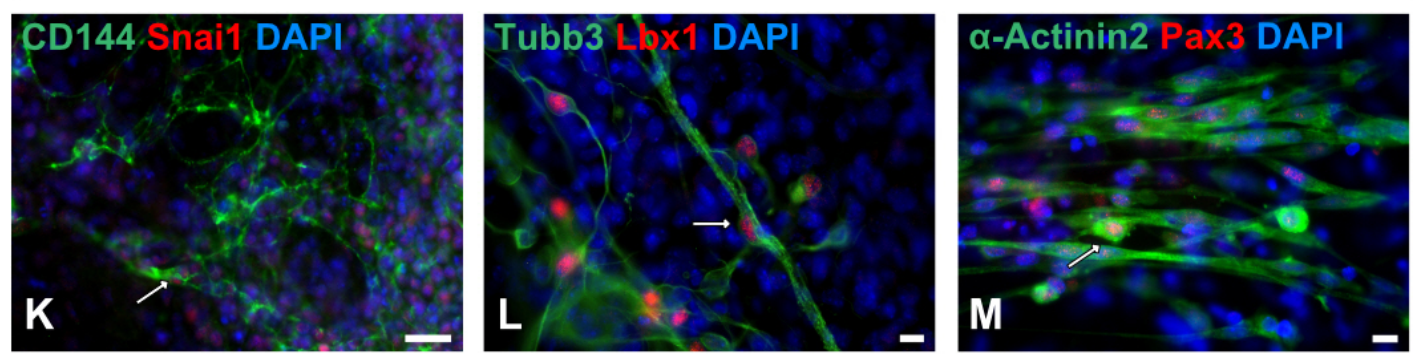

Fig. 2. Immunofluorescence analyses of cardiac and non-cardiac ES cell-derived progeny. (A $\sim E, G \sim J)$ Representative immunofluorescence analyses of isolated beating cardiac clusters using CNC-associated (all in red) and the cardiomyocyte-specific markers $\alpha$-Actinin2 and Troponin T (both in green) (A, B, D, E, G J: 5+7+1d; C: 5+4+1d). (F) Staining of non-isolated ES cell-derived cardiac progeny at stage 5+9d using $\alpha$-Actinin2 and ET-AR (endothelin-1). $(\mathrm{K} \sim \mathrm{M})$ Immunofluorescence analyses of non-cardiac ES cell-derived progeny using CNC-associated markers (all in red) and endothelial cell- (CD144/VE-Cadherin), neuronal cell- (Tubb3) and skeletal muscle cell-specific ( $\alpha$-Actinin2) markers (K: $5+4 \mathrm{~d} ; \mathrm{L}, \mathrm{M}: 5+15 \mathrm{~d}$ ). White arrows indicate co-expression. Nuclei were counterstained with DAPI in blue. Bars: $50 \mu \mathrm{m}(\mathrm{D}, \mathrm{L}) ; 20 \mu \mathrm{m}(\mathrm{B}, \mathrm{C}, \mathrm{F} \sim \mathrm{K}, \mathrm{M}) ; 10 \mu \mathrm{m}(\mathrm{A}, \mathrm{E})$. 


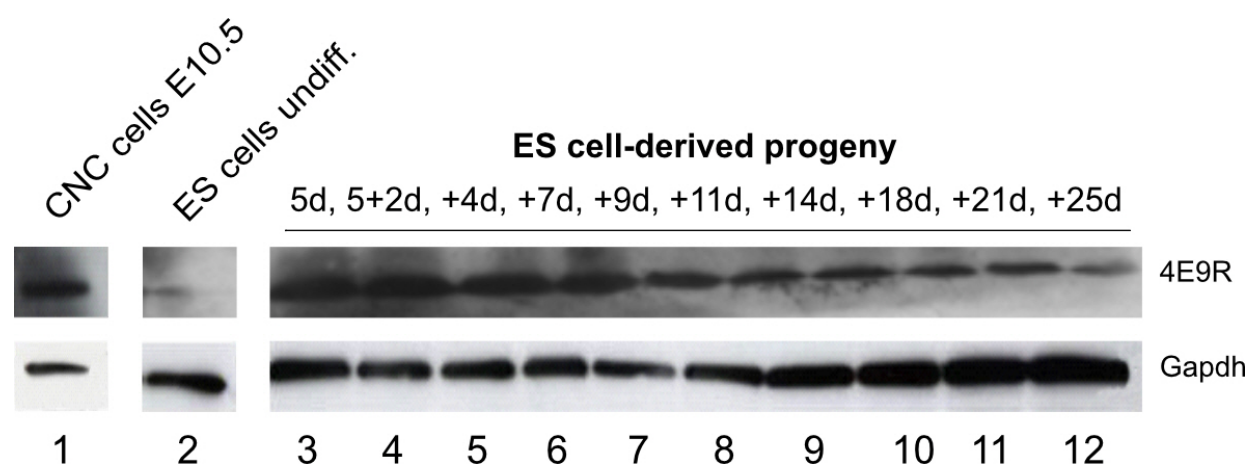

Fig. 3. Western blot analyses of primary $\mathrm{CNC}$ cells and $\mathrm{ES}$ cell specimen using the $4 \mathrm{E} 9 \mathrm{R}$ antibody. Comparative immunoblot analysis of CNC cells (1) as well as ES cell-derived specimens at various differentiation stages: 2) undifferentiated ES cells, 3) $5 \mathrm{~d}$ EBs; 4) $5+2 \mathrm{~d}$; 5) $5+4 d$; 6) $5+7 d$; 7) $5+9 d$; 8) $5+11 d$; 9) $5+14 d$; 10) $5+18 d$; 11) $5+21 d$; 12) was performed using $4 \mathrm{E} 9 R$ antibody. For protein integrity the reference protein Gapdh was used as loading control. E: embryonic day, undiff.: undifferentiated, d: day, EB: embryoid body.

\section{The application of 4E9R enables the unambiguous identification of ES cell-derived CNC-like cells}

To identify potential ES cell-derived CNC-like cells, IF analyses were performed using the $\mathrm{NC} / \mathrm{CNC}$ cell-specific antibody, 4E9R $(22,23)$. To investigate the staining pattern of $4 \mathrm{E} 9 \mathrm{R}$ in non-NC/CNC-derivatives such as skeletal muscle cells, ES cell-derived cells were stained with 4E9R and the skeletal muscle cell marker $\alpha$-Actinin2 (Fig. 4A). At the more advanced differentiation stage $5+26 \mathrm{~d}$, the cells displayed only a positive immunoreactivity for $\alpha$-Actinin2, but not for 4E9R (Fig. 4A). Thereafter, ES cell-derived smooth muscle and neuronal cells, which represent derivatives of the $\mathrm{NC} / \mathrm{CNC}$, were stained with $4 \mathrm{E} 9 \mathrm{R}$ and cell lineage-specific markers such as $\alpha$-Actin 2 for smooth muscle cells as well as Nestin and Tubb3 for neuronal cells (Fig. $4 \mathrm{~B} \sim \mathrm{D}$ ). IF analyses revealed a positive staining for 4E9R either with $\alpha$-Actin2 (Fig. 4B), Nestin (Fig. 4C) or Tubb3 (Fig. 4D) at intermediate differentiation stages $(5+5 d-5+9 d)$. Subsequently, ES cell derivatives were stained with 4E9R and selected CNC-associated markers (Supplementary Table S4). Due to the modified staining protocol, using formalin/MeOH fixation, only Mef2c (Fig. 4E), Cx43 (Fig. 4F), Hand2 (Fig. 4G and 4J), Pax3 (Fig. $4 \mathrm{H})$ and Lbxl (Fig. 4I) showed a positive immunoreactivity, when stained together with the NC/CNC-specific marker $4 \mathrm{E} 9 \mathrm{R}$ at various differentiation stages. In all previous staining analyses, an intermediate filament-like staining pattern was observed for 4E9R, but the co-application of 4E9R with $\mathrm{Cx} 43$ revealed for the first time a striated/sarcomere-like pattern for 4E9R (Fig. 4F).

\section{ES cell-derived cardiomyocytes show a spatiotemporal restricted expression pattern of $4 \mathrm{E} 9 \mathrm{R}$}

To examine the striated/sarcomere-like staining pattern of $4 \mathrm{E} 9 \mathrm{R}$, isolated beating cardiac clusters were co-stained with the 4E9R antibody and various sarcomere-specific antibodies against Titin, $\alpha$-Actinin2 and Mlc2a (Supplementary Fig. S2). A small subpopulation of early ES cellderived cardiomyocytes showed a positive co-expression of Titin (Supplementary Fig. S2A and S2A'), $\alpha$-Actinin2 (Supplementary Fig. S2B and S2B') and Mlc2a (Supplementary Fig. S2C and S2C') with 4E9R, respectively. Remarkably, in those cells a clear, striated, sarcomere-like pattern for 4E9R was detected, but no overlap with the assessed sarcomere proteins. At the more advanced differentiation stage $5+14 \mathrm{~d}$, the striated-like pattern of $4 \mathrm{E} 9 \mathrm{R}$ changed into a dotted, diffuse, non-filamentous and nonstriated staining pattern, while the Titin (Supplementary Fig. S2D and S2D'), $\alpha$-Actinin2 (Supplementary Fig. S2E and S2E') and Mlc2a (Supplementary Fig. S2F and S2F') pattern did not change.

\section{Most co-immunoprecipitated proteins represent isoforms of myosin, light polypeptide 6}

To elucidate the expression pattern of the NC/CNCspecific marker 4E9R, various heart specimens, including primary CNC cells at E10.5, were analyzed by Western blot (Fig. 5A). The detected immunogen of 4E9R had a molecular size of $\sim 15 \mathrm{kDa}$. In primary $\mathrm{CNC}$ cells (E10.5), embryonic heart tissues $(\mathrm{E} 10.5 \sim \mathrm{E} 17.5)$ and $\mathrm{P} 8$ heart tissue, strong 4E9R immunosignals were observed. Whereas, at $\mathrm{P} 15$ and adult heart tissue, almost no $4 \mathrm{E} 9 \mathrm{R}$ reactive protein was detectable (Fig. 5A).

To identify the unknown epitope(s) recognized by the 4E9R antibody, IP analyses with protein lysates isolated from whole-mount embryos, primary CNC cells, embryonic and adult heart tissue, and ES cell-derived specimen were performed (Fig. 5B). SDS-PAGE and Coomassie 


\section{Non-CNC cell marker: $5+26 d$}

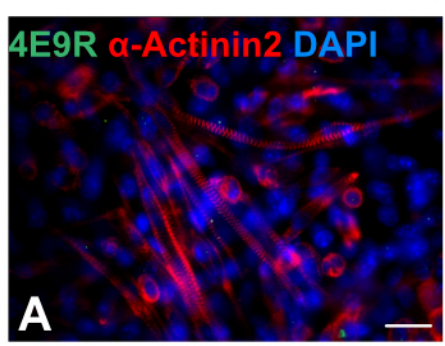

CNC lineage markers: A: 5+5d; B: $5+7 d$; C: $5+9 d$

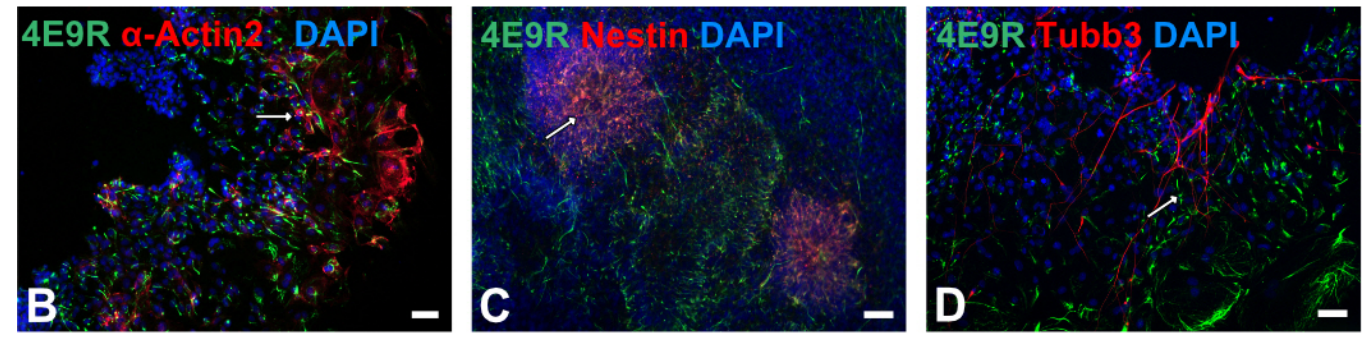

CNC-associated marker: G: 5+4d; H: 5+9d; I: 5+14d; J: 5+18d; K, L: 5+25d
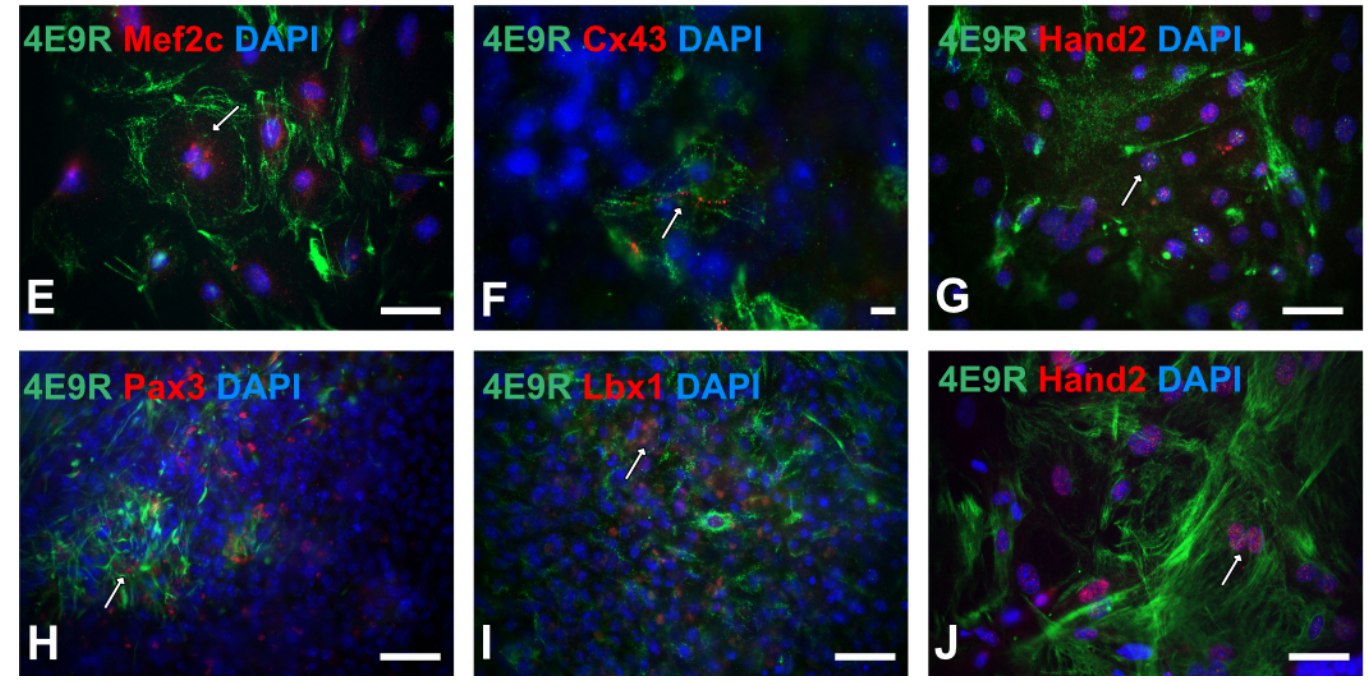

Fig. 4. Immunofluorescence analyses of multilineage ES cell-derivatives using the NC/CNC-specific marker 4E9R. (A) Immunocytochemistry of ES cell-derived non-CNC-related skeletal muscle cells applying 4E9R (green) and the skeletal muscle cell-specific antibody $\alpha$-Actinin2 (red). (B D): Representative immunofluorescence staining of ES cell-derived CNC progeny using 4E9R (in green) and lineage-specific markers as $\alpha$-Actin2 for smooth muscle cells (B) as well as Nestin (C) and Tubb3 (D) for neuronal cells (all in red). (E J) Immunofluorescence analysis of ES cell-derived progeny using 4E9R (in green) and CNC-associated markers such as Mef2c (E), Cx43 (F), Hand2 (G, J), Pax3 $(\mathrm{H})$ and Lbx1 (I) (all in red). White arrows indicate co-expression. Nuclei were counterstained using DAPI (blue). Bars: $50 \mu \mathrm{m}(\mathrm{A} \sim \mathrm{E}$, $\mathrm{G} \sim \mathrm{J}) ; 10 \mu \mathrm{m}(\mathrm{F})$.

Blue staining identified multiple co-precipitated proteins. A consistent triplet banding pattern ranging from 15 to $17 \mathrm{kDa}$ was detectable in almost every IP sample, except for the adult heart tissue (Fig. 5B'). In total, 17 bands were selected for nLC-ESI-MSMS analysis. IP results were analyzed using the Mascot server database tool (matrix- science.com) and classified according to the identified amino acid sequences (matched peptides), molecular weight and the Mascot ion score. For reliable protein identification, the Mascot ion score should be around 100 (www.matrixscience.com). The molecular weight, scores $(>100)$, sequence coverage and matched peptides of 


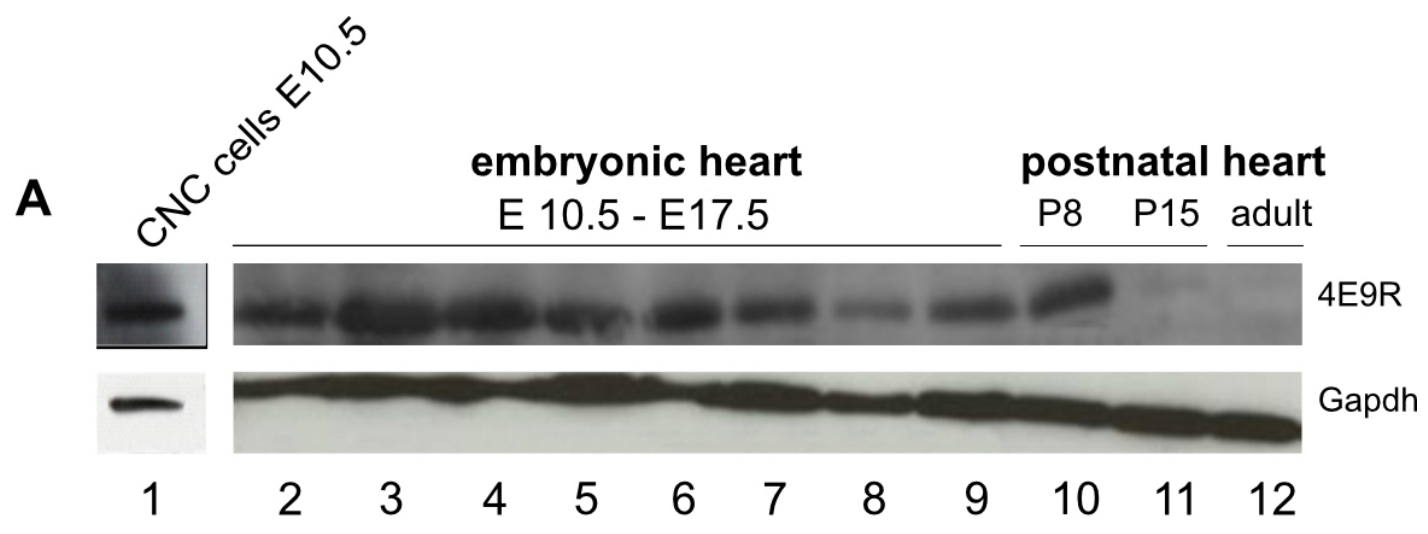

B $\mathrm{kDa}$

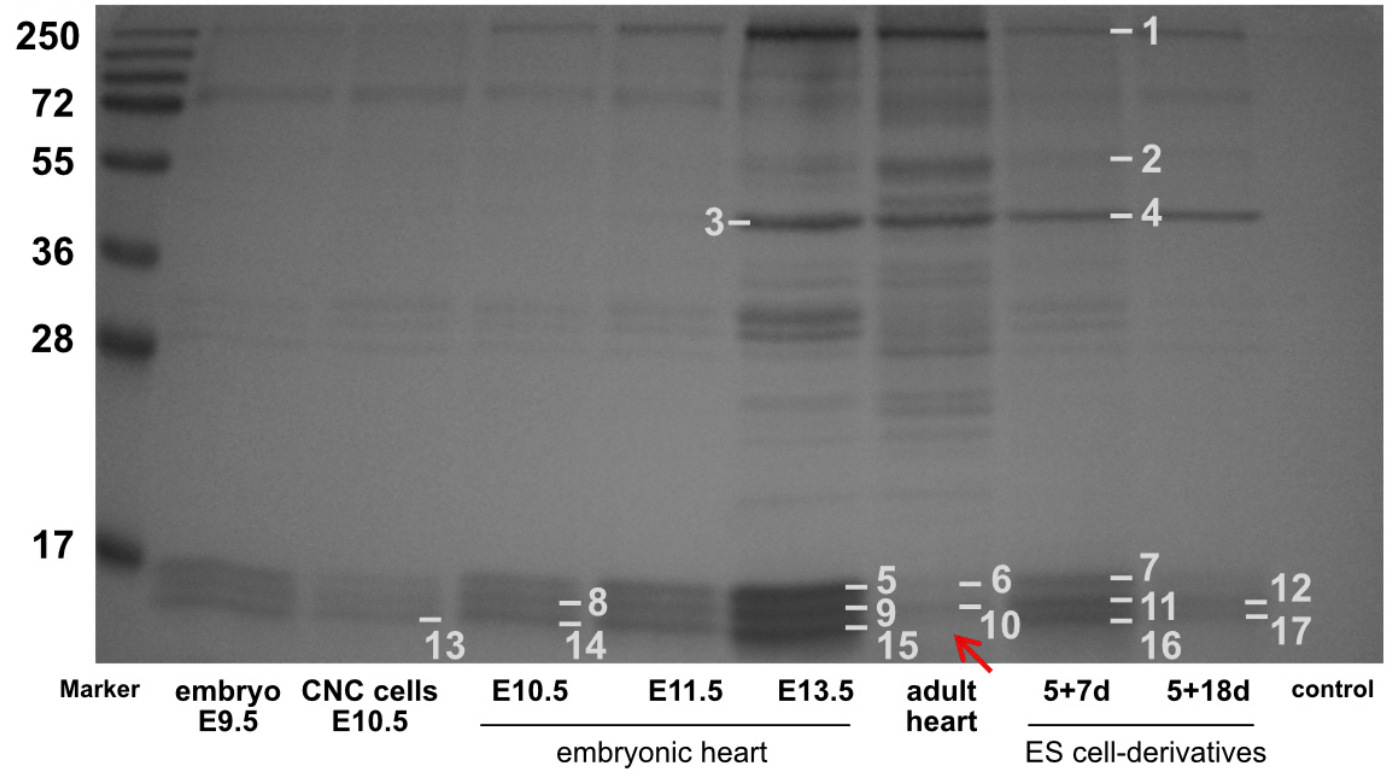

B'

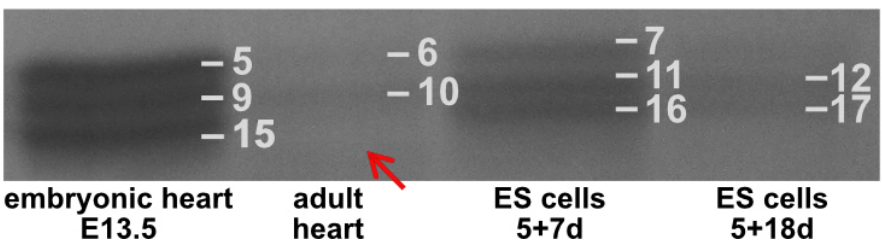

Fig. 5. Western blot and IP analyses of various heart specimen. (A) Comparative Western blot analysis of NC cells, embryonic, postnatal and adult heart tissue immunostained against 4E9R and Gapdh: 1) CNC cells E10.5; 2 9) embryonic heart tissue (E10.5 E17.5); 10) postnatal heart P8; 11) postnatal heart P15; 12) adult heart. For protein integrity the reference protein Gapdh was used as loading control. E: embryonic day, P: postnatal day, d: day. (B) Coomassie Blue stained SDS-PAGE resulting from immunoprecipitation with 4E9R antibody. The IP was performed with protein lysates of several tissue and ES cell-derived specimen at various differentiation stages. Numbers $1 \sim 17$ indicate the gel bands analyzed by nLC-ESI-MSMS. All investigated samples showed a triplet band pattern between 15 and $17 \mathrm{kDa}$ except the adult heart tissue, where the lowest band is missing (indicated by the red arrow). ( $\mathrm{B}^{\prime}$ ) Magnified section showing a selection of analyzed samples including adult heart tissue. Identified proteins and corresponding accession numbers are listed in Supplementary Tables S5 and S6.

co-immunoprecipitated proteins are presented in Supplementary Tables S5 and S6.

Co-immunoprecipitated proteins in lanes 1 4 (Fig. 5B, Supplementary Table S5) represent several isoforms of myosin 10, vimentin, alpha and gamma actin with molecular weights between 39 and $232 \mathrm{kDa}$. Based on immunoblot results, the as yet to be identified immunogenic protein had a molecular weight of $\sim 15 \mathrm{kDa}$. Therefore, pro- 
teins with different molecular weights were excluded from further analyses, but may represent potential binding or interaction partners of the 4E9R reactive protein. Co-precipitated proteins in lanes $5 \sim 8$ (Fig. 5B, Supplementary Table S5) were ribosomal proteins, cytochromes and histones.
Remarkably, several isoforms of 'myosin light polypeptide 6 (Mlc-3)' were identified in bands 9 to 17, with varying scores and sequence coverage (Fig. 5B, Supplementary Table S6). The lowest scores $(<50)$ were observed in lanes 9 (score 43) and 15 (both E13.5, score 42), 13 (CNC cells, score 35) and 10 (adult heart, score 46). Intermediate
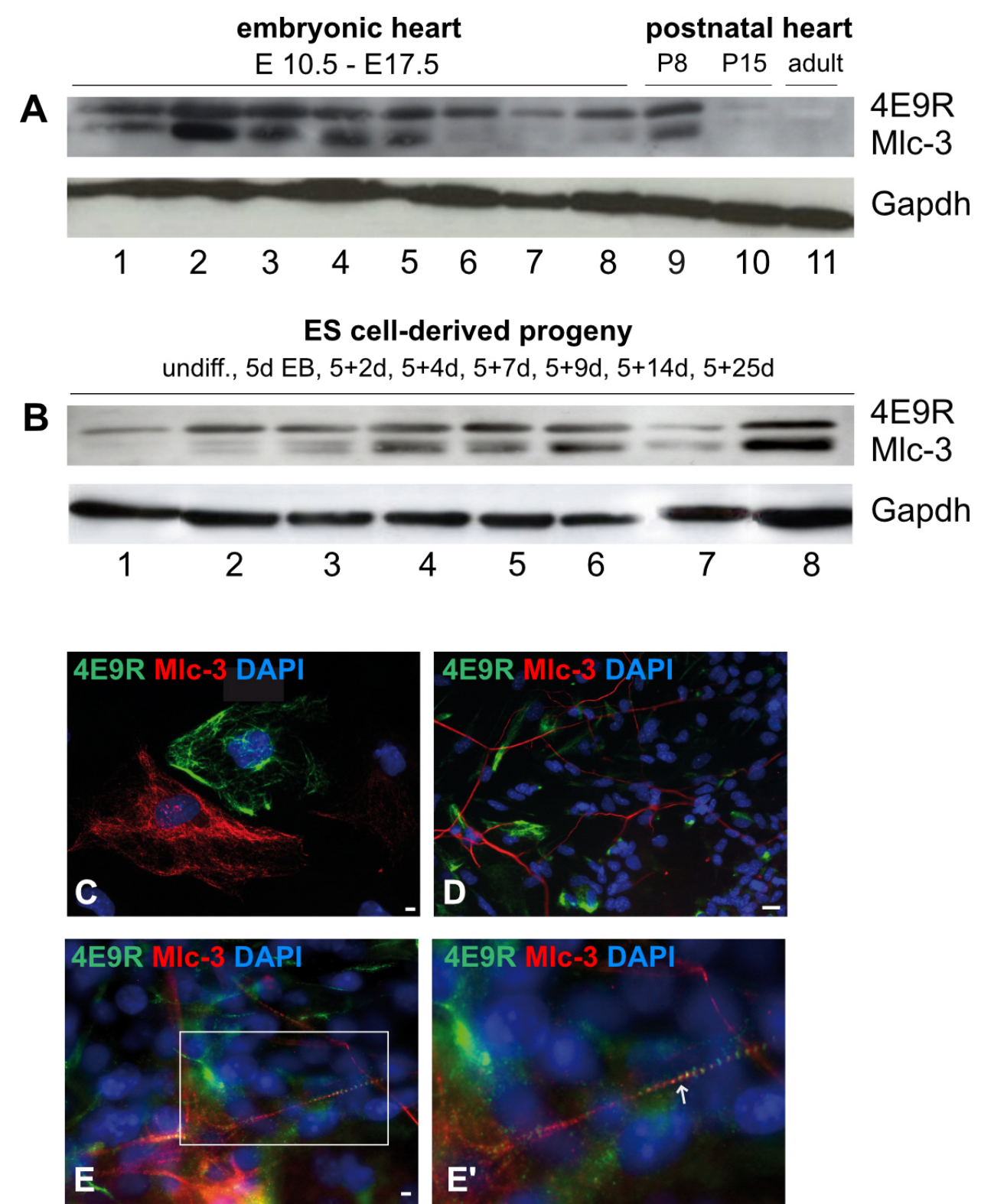

Fig. 6. Comparative expression analyses elucidating the respective immunoreactivity of Mlc-3 and 4E9R. (A) Western blot analysis of primary murine heart tissues immunostained with Mlc-3 (13 kDa, predicted: $17 \mathrm{kDa})$ and 4E9R (15 kDa). $1 \sim 8$ embryonic heart tissues (1: E10.5; 2: E11.5; 3: E12.5; 4: E13.5; 5: E14.5; 6: E15.5, 7: E16.5; 8: E17.5); 9) postnatal heart tissue P8; 10) postnatal heart tissue P15; 11) adult heart tissue. (B) Immunoblot of undifferentiated (undiff.) and differentiated ES cell-derived specimens. 1) undiff. ES cells; 2) 5d EBs; 3) $5+2 d$; 4) $5+4 d$; 5) $5+7 d$; 6) $5+9 d$; 7) $5+14 d$; 8) $5+25 d$. As a loading control, the reference protein Gapdh $(40 \mathrm{kDa})$ was used. $(C \sim E)$ Immunofluorescence analyses comparing the staining patterns of Mlc-3 (red) and 4E9R (green) in non-cardiac (C; $5+5 \mathrm{~d})$, neuronal (D; $5+7 d)$ and cardiac $\left(E, E^{\prime} ; 5+7 d\right)$ ES cell-derived progeny. The white box indicates the magnified area (E), whereas the white arrow shows the co-labeling of Mlc-3 and 4E9R (E'). Nuclei were counterstained using DAPI (blue). Bars: $50 \mu \mathrm{m}(\mathrm{C}), 20 \mu \mathrm{m}(\mathrm{D}, \mathrm{E})$. 
scores $(>50,<100)$ were reported for lanes 11 (score 59), 16 (both $5+7 \mathrm{~d}$, score 62) and 14 (E10.5 heart, score 92). Proteins with the highest scores and coverage were observed in lanes 12 (score 151) and 17 (both $5+18 \mathrm{~d}$, score 151) (Fig. 5B, Supplementary Table S6). Interestingly, no protein band of this molecular weight was detected in adult heart tissue.

\section{Mlc-3 and 4E9R antibody displayed a similar but not identical expression pattern}

To investigate, whether Mlc-3 contains the unknown epitope recognized by 4E9R, Western blot (Fig. 6A and $6 \mathrm{~B})$ as well as IF analyses of early, unspecified non-cardiac $(5+5$ d, Fig. 6C), neuronal $(5+7$ d, Fig. 6D) and cardiac $(5+7$ d, Fig. 6E) ES cell derivatives were performed. For Western blot analysis, several embryonic and postnatal heart (Fig. 6A) as well as ES cell-derived specimens (Fig. $6 \mathrm{~B})$ were investigated by the co-application of $4 \mathrm{E} 9 \mathrm{R}$ and Mlc3- antibodies. The immunoblot analysis revealed a similar expression pattern for 4E9R and Mlc-3 in embryonic and postnatal primary heart tissues except for developmental stages E15.5 (Fig. 6A, (6)), E16.5 (Fig. 6A, (7)) and E17.5 (Fig. 6A, (8)) where no Mlc-3 expression was detectable. However, both antibodies did not show a positive staining in the postnatal stage P15 and in the adult heart tissue. ES cell-derived specimens showed as well a similar expression pattern for 4E9R and Mlc-3, except in undifferentiated ES cells (Fig. 6B, (1)) and the early differentiation stages 5d EB (Fig. 6B, (2)) and 5+2d (Fig. $6 \mathrm{~B},(3))$. Despite similar expression pattern of $4 \mathrm{E} 9 \mathrm{R}$ and Mlc-3 in all assessed specimens, both recognized epitopes displayed different molecular weights (Fig. 6A and 6B). Comparative IF analyses showed as well no overlapping staining pattern for Mlc-3 and 4E9R (Fig. 6C $\sim \mathrm{E}$ ). However, a co-expression within in the same cell but no overlapping staining pattern of 4E9R and Mlc-3 was observed in cardiac progeny (Fig. 6E and 6E'). Remarkably, the anti-Mlc-3 antibody displayed a filamentous staining pattern in non-cardiac cells (Fig. 6C and 6D) and a striated staining pattern in cardiac cells (Fig. 6E and 6E'), similar to the 4E9R antibody.

\section{Discussion}

Pluripotent ES cells represent an unique cell resource for numerous applications, as they are characterized by a nearly unlimited self-renewal and differentiation capacity (3). Besides the capacity to develop into derivatives of the three primary germ layers, mouse and human pluripotent stem cells have also been shown to generate cell deriva- tives of the 'fourth' germ layer, the NC (31).

In an earlier study, we had differentiated murine ES cells according to a mesodermal-lineage promoting protocol and performed comparative expression analyses of undifferentiated and differentiated ES cell specimens at stage $5+9 d$ (6). Affymetrix gene chip-based expression profiling has provided first evidence that ES cells can be differentiated into NC/CNC-like cells as an upregulation of NC and CNC markers in differentiated specimens was observed (Rolletschek, et al., unpublished) (6). For verification and further molecular characterization, we differentiated murine ES cells of line R1 according to the mesodermal-lineage promoting protocol as described earlier (6). Initial, morphological assessment revealed ES cell progeny of the mesodermal lineage, but also ectodermal derivatives. For the establishment of appropriate CNC cell models, a heterogenous mixture of diverse cell types is a crucial prerequisite for mimicking the in vivo situation at its best. Thus, the existence of different cell types in our ES cell cultures hold a great advantage for prospective CNC cell models.

Subsequent expression analyses in our current study on mRNA and protein level verified the Affymetrix gene chip data as ES cell-derived progeny showed a strong expression of selected NC/CNC-associated markers. However, selected CNC-associated markers are also expressed by other cell types, in particular cardiac cells (21). In order to confirm the identity of potential ES cell-derived NC/ CNC-like cells, a NC-specific antibody (4E9R) was applied (22). Several studies had previously verified this antibody as a suitable NC cell-specific marker (22, 32-34), and it was also demonstrated that it identifies CNC cells (23). Furthermore, it was shown that the immunoreactivity of $4 \mathrm{E} 9 \mathrm{R}$ is restricted to early developmental stages, as with progressing development its reactivity is decreasing (22).

To confirm its specificity also for murine ES cells, we co-stained ES cell-derived smooth muscle and neuronal cells, which represent derivatives of the NC/CNC (8), applying the 4E9R antibody combined with lineage-specific markers such as $\alpha$-Actin2 (smooth muscle cells), Nestin and Tubb3 (neuronal cells). In line with earlier studies (22), with advancing development, the number of 4E9Rpositive cells seemed to decrease and only a partial co-expression of $4 \mathrm{E} 9 \mathrm{R}$ with the lineage-specific markers was detectable. In addition, we implemented ES cell-derived skeletal muscle cells, which are no NC/CNC-derivatives and performed a co-staining using 4E9R antibody and the lineage-specific marker $\alpha$-Actinin2. Remarkably, ES cellderived skeletal muscle cells showed no co-expression with 
4E9R.

Finally, we could confirm the terminable expression pattern of 4E9R in our study by Western blot analysis of ES cell and mouse heart specimens at various developmental stages.

In conclusion, the $4 \mathrm{E} 9 \mathrm{R}$ antibody represents a perfect tool for unambiguous identification of ES cell-derived $\mathrm{NC} / \mathrm{CNC}$-like cells. Immunofluorescence analyses using 4E9R and CNC-associated markers revealed a partial overlap. Due to the modified staining protocol for 4E9R (formaldehyde $/ \mathrm{MeOH}$ fixation at $-20^{\circ} \mathrm{C}$ ), a co-staining for not all selected CNC-associated markers worked out although they showed an immunoreactivity in the nonmodified procedure using PFA (at RT) for fixation.

However, our results indicate that murine ES cells can be differentiated into NC/CNC-like cells. To strengthen these results, further CNC-associated markers need to be tested in combination with 4E9R.

In addition, we monitored that the staining pattern generated by $4 \mathrm{E} 9 \mathrm{R}$ changed from filamentous to striated/sarcomere-like as seen in Cx43-positive cells. As $\mathrm{Cx} 43$ is also a typical marker for cardiomyocytes, 4E9R was furthermore applied together with the sarcomere-specific markers (Titin, $\alpha$-Actinin2, Mlc2a) on isolated cardiac clusters. Immunofluorescence analysis revealed a striated, but non-overlapping staining pattern of 4E9R in early cardiomyocytes. In more advanced differentiation stages, the striated pattern of 4E9R changed again, into a dotted and diffuse staining.

To identify the still unknown epitope/s recognized by 4E9R, IP analyses were performed. The most abundant co-precipitated proteins belonged to the Mlc-3, myosin light chain, smooth muscle and non-muscle protein family. Several isoforms of Mlc-3 of varying molecular weights, scores and sequence coverages were identified. To follow up these findings, Western blot analyses were performed which revealed similar expression patterns of 4E9R and Mlc-3 but different molecular weights. Subsequent IF analyses using both antibodies showed no co-expression in non-cardiac cells and a co-expression but no overlapping staining pattern in cardiac progeny.

This data suggests, that the 4E9R immunogen could represent a specific spatiotemporally expressed as yet to be identified isoform of Mlc-3. Its immunoreactivity in cardiomyocytes might point to a differentiation of $\mathrm{CNC}$ cells into early cardiomyocytes as already described in zebrafish (35-37) and mice (31). First evidence was generated in mice as it was shown that CNC cells are able to migrate into the developing heart, where they persist as dormant tissue-specific progenitors until adulthood.
Upon appropriate stimulation they can give rise to NC cell derivatives, including peripheral neurons, glia, smooth muscle cells and cardiomyocytes $(38,39)$. These findings were lately supported by a genetic fate-mapping approach which showed that $c$ Kit delineates CNC progenitor cells, which exhibit the capacity to differentiate into cardiomyocytes and other CNC derivatives (40).

Our data suggest that murine ES cells have the capacity to differentiate into NC/CNC-like cells in vitro, as demonstrated by the immunoreactivity of CNC-associated markers and the NC/CNC cell-specific marker, 4E9R. We also investigated the still unknown immunogen of 4E9R and could show that it might represent a spatiotemporally expressed isoform of Mlc-3. Whether ES cell models can properly simulate the differentiation of CNC cells into cardiomyocytes and whether the $4 \mathrm{E} 9 \mathrm{R}$ reactive protein contributes to CNC cells in early cardiomyogenic development remains to be elucidated.

Finally, our data clearly illustrates that ES cells can be differentiated into CNC-like cells and thereby providing a crucial basis for the establishment of novel $\mathrm{CNC}$ cell models.

\section{Acknowledgments}

The authors are grateful to Prof. Kazuo Ito for providing the $4 \mathrm{E} 9 \mathrm{R}$ antibody and relevant staining protocols as well as to Prof. Anna M. Wobus for valuable advice and comments. The authors thank also Sandra Hoffmann and Claire Bacon for critical reading, editing and helpful comments on the manuscript.

This work was funded by the Institute for Biological Interfaces at the Karlsruhe Institute of Technology (KIT) in Eggenstein-Leopoldshafen, Germany and was financially supported by the Heidelberg University Hospital, Heidelberg, Germany (G.A. Rappold, B. Niesler).

\section{Potential Conflict of Interest}

The authors have no conflicting financial interest.

\section{Supplementary Materials}

Supplementary data including six tables and two figure can be found with this article online at http://pdf.medrang.co.kr/paper/pdf/IJSC/IJSC-13-s19069.pdf.

\section{References}

1. Evans MJ, Kaufman MH. Establishment in culture of pluripotential cells from mouse embryos. Nature 1981;292:154156 
2. Martin GR. Isolation of a pluripotent cell line from early mouse embryos cultured in medium conditioned by teratocarcinoma stem cells. Proc Natl Acad Sci U S A 1981;78: 7634-7638

3. Wobus AM. Potential of embryonic stem cells. Mol Aspects Med 2001;22:149-164

4. Prelle K, Zink N, Wolf E. Pluripotent stem cells--model of embryonic development, tool for gene targeting, and basis of cell therapy. Anat Histol Embryol 2002;31:169-186

5. Boheler KR, Czyz J, Tweedie D, Yang HT, Anisimov SV, Wobus AM. Differentiation of pluripotent embryonic stem cells into cardiomyocytes. Circ Res 2002;91:189-201

6. Rolletschek A, Schroeder IS, Schulz H, Hummel O, Huebner N, Wobus AM. Characterization of mouse embryonic stem cell differentiation into the pancreatic lineage in vitro by transcriptional profiling, quantitative RT-PCR and immunocytochemistry. Int J Dev Biol 2010;54:41-54

7. Le Douarin N. The neural crest. Cambridge: Cambridge University Press; 1982. xi-259

8. Gilbert SF. The neural crest. In: Gilbert SF, editor. Developmental biology. 6th ed. Sunderland: Sinauer Associates; 2000.

9. Kirby ML, Gale TF, Stewart DE. Neural crest cells contribute to normal aorticopulmonary septation. Science 1983; 220:1059-1061

10. Kirby ML, Waldo KL. Neural crest and cardiovascular patterning. Circ Res 1995;77:211-215

11. Miyagawa-Tomita S, Arima Y, Kurihara H. The "Cardiac Neural Crest" concept revisited. In: Nakanishi T, Markwald RR, Baldwin HS, Keller BB, Srivastava D, Yamagishi $\mathrm{H}$, editors. Etiology and Morphogenesis of Congenital Heart Disease: From Gene Function and Cellular Interaction to Morphology. Tokyo: Springer; 2016. 227-232

12. Besson WT 3rd, Kirby ML, Van Mierop LH, Teabeaut JR 2nd. Effects of the size of lesions of the cardiac neural crest at various embryonic ages on incidence and type of cardiac defects. Circulation 1986;73:360-364

13. Bockman DE, Redmond ME, Waldo K, Davis H, Kirby ML. Effect of neural crest ablation on development of the heart and arch arteries in the chick. Am J Anat 1987;180: 332-341

14. Creazzo TL, Brotto MA, Burch J. Excitation-contraction coupling in the day 15 embryonic chick heart with persistent truncus arteriosus. Pediatr Res 1997;42:731-737

15. Nosek TM, Fogaça RT, Hatcher CJ, Brotto MA, Godt RE. Effect of cardiac neural crest ablation on contractile force and calcium uptake and release in chick heart. Am J Physiol 1997;273:H1464-H1471

16. Conway SJ, Henderson DJ, Kirby ML, Anderson RH, Copp AJ. Development of a lethal congenital heart defect in the splotch (Pax3) mutant mouse. Cardiovasc Res 1997;36:163173

17. Conway SJ, Godt RE, Hatcher CJ, Leatherbury L, Zolotouchnikov VV, Brotto MA, Copp AJ, Kirby ML, Creazzo TL. Neural crest is involved in development of abnormal myocardial function. J Mol Cell Cardiol 1997;29:2675-2685
18. Epstein JA, Li J, Lang D, Chen F, Brown CB, Jin F, Lu MM, Thomas M, Liu E, Wessels A, Lo CW. Migration of cardiac neural crest cells in Splotch embryos. Development 2000;127:1869-1878

19. Li J, Liu KC, Jin F, Lu MM, Epstein JA. Transgenic rescue of congenital heart disease and spina bifida in Splotch mice. Development 1999;126:2495-2503

20. Keyte A, Hutson MR. The neural crest in cardiac congenital anomalies. Differentiation 2012;84:25-40

21. Brand T. Heart development: molecular insights into cardiac specification and early morphogenesis. Dev Biol 2003;258:1-19

22. Kubota Y, Morita T, Ito K. New monoclonal antibody (4E9R) identifies mouse neural crest cells. Developmental Dynamics 1996;206:368-378

23. Youn YH, Feng J, Tessarollo L, Ito K, Sieber-Blum M. Neural crest stem cell and cardiac endothelium defects in the TrkC null mouse. Mol Cell Neurosci 2003;24:160-170

24. Nagy A, Rossant J, Nagy R, Abramow-Newerly W, Roder JC. Derivation of completely cell culture-derived mice from early-passage embryonic stem cells. Proc Natl Acad Sci U S A 1993;90:8424-8428

25. Wobus AM, Guan K, Yang HT, Boheler KR. Embryonic stem cells as a model to study cardiac, skeletal muscle, and vascular smooth muscle cell differentiation. Methods Mol Biol 2002;185:127-156

26. Hoffmann S, Schmitteckert S, Griesbeck A, Preiss H, Sumer S, Rolletschek A, Granzow M, Eckstein V, Niesler B, Rappold GA. Comparative expression analysis of Shox2deficient embryonic stem cell-derived sinoatrial node-like cells. Stem Cell Res 2017;21:51-57

27. Schroeder IS, Rolletschek A, Blyszczuk P, Kania G, Wobus AM. Differentiation of mouse embryonic stem cells to insulin-producing cells. Nat Protoc 2006;1:495-507

28. Wiese C, Nikolova T, Zahanich I, Sulzbacher S, Fuchs J, Yamanaka S, Graf E, Ravens U, Boheler KR, Wobus AM. Differentiation induction of mouse embryonic stem cells into sinus node-like cells by suramin. Int J Cardiol 2011; 147:95-111

29. Maltsev VA, Wobus AM, Rohwedel J, Bader M, Hescheler J. Cardiomyocytes differentiated in vitro from embryonic stem cells developmentally express cardiac-specific genes and ionic currents. Circ Res 1994;75:233-244

30. Snider P, Olaopa M, Firulli AB, Conway SJ. Cardiovascular development and the colonizing cardiac neural crest lineage. ScientificWorldJournal 2007;7:1090-1113

31. Liu JA, Cheung M. Neural crest stem cells and their potential therapeutic applications. Dev Biol 2016;419:199-216

32. Kawasaki T, Bekku Y, Suto F, Kitsukawa T, Taniguchi M, Nagatsu I, Nagatsu T, Itoh K, Yagi T, Fujisawa H. Requirement of neuropilin 1-mediated Sema3A signals in patterning of the sympathetic nervous system. Development 2002; 129:671-680

33. Kubota Y, Ito K. Chemotactic migration of mesencephalic neural crest cells in the mouse. Dev Dyn 2000;217:170-179

34. Labosky PA, Kaestner KH. The winged helix transcription 
factor Hfh2 is expressed in neural crest and spinal cord during mouse development. Mech Dev 1998;76:185-190

35. Cavanaugh AM, Huang J, Chen JN. Two developmentally distinct populations of neural crest cells contribute to the zebrafish heart. Dev Biol 2015;404:103-112

36. Li YX, Zdanowicz M, Young L, Kumiski D, Leatherbury L, Kirby ML. Cardiac neural crest in zebrafish embryos contributes to myocardial cell lineage and early heart function. Dev Dyn 2003;226:540-550

37. Sato M, Yost HJ. Cardiac neural crest contributes to cardiomyogenesis in zebrafish. Dev Biol 2003;257:127-139

38. Tamura Y, Matsumura K, Sano M, Tabata H, Kimura K, Ieda M, Arai T, Ohno Y, Kanazawa H, Yuasa S, Kaneda R, Makino S, Nakajima K, Okano H, Fukuda K. Neural crest-derived stem cells migrate and differentiate into cardiomyocytes after myocardial infarction. Arterioscler Thromb Vasc Biol 2011;31:582-589

39. Tomita Y, Matsumura K, Wakamatsu Y, Matsuzaki Y, Shibuya I, Kawaguchi H, Ieda M, Kanakubo S, Shimazaki T, Ogawa S, Osumi N, Okano H, Fukuda K. Cardiac neural crest cells contribute to the dormant multipotent stem cell in the mammalian heart. J Cell Biol 2005;170:1135-1146

40. Hatzistergos KE, Takeuchi LM, Saur D, Seidler B, Dymecki SM, Mai JJ, White IA, Balkan W, KanashiroTakeuchi RM, Schally AV, Hare JM. cKit + cardiac progenitors of neural crest origin. Proc Natl Acad Sci U S A 2015;112:13051-13056 